\title{
Application of selected methods of digital simulation to analyse dynamic impact of driven pneumatic wheel on soil in agrotechnical treatments and forestry to limit negative impact on the environment
}

\author{
Włodzimierz Malesa ${ }^{1, *}$, and Marek Kopacz ${ }^{1}$ \\ ${ }^{1}$ Warsaw University of Technology, ul. Łukasiewicza 17, 09-400 Płock, Poland
}

\begin{abstract}
Loads transmitted by mechanical vehicles to soil result in its deformation and compaction. Increasingly bigger and more efficient machines affect the base they move on to a significantly greater extent. The purpose of this study with the use of digital simulation is to reduce expenses on costly experimental studies with the use of off-road vehicles or specially developed laboratory machines. The simulations were conducted using the Mechanical Event Simulation module, which is a part of the Autodesk Simulation Mechanical software. For each step, the simulation program provides the value of stress in all nodes of the base grid. The stress values obtained via dynamic simulations are consistent with the values registered under laboratory conditions. When classical experiments are replaced with numerical methods, not only the cost is reduced, but also the impact of weather conditions on measurement results is avoided and the time required for the study is shortened. The use of the described methods allows for design and selection parameters of exploitation pneumatics drive mechanism, which will significantly reduce the negative impact on the natural environment by machines in agrotechnical treatments and forestry. This is related to the environmental protection issues.
\end{abstract}

\section{Introduction}

Loads transmitted by mechanical vehicles to soil result in its deformation and compaction. Increasingly bigger and more efficient machines affect the base they move on to a significantly greater extent. Studies confirm that multiple passages of machines result in consolidation of soil, which results in significantly decreased yield of plant cultivation $[5,8]$.

The machines' ability to function effectively in the field depends on the physical properties of the base. Thus, mechanical properties of soil, as well as the size and type of impact of the wheel driving mechanism on the base must be considered when off-road vehicles are designed.

* Corresponding author: wlodzimierz.malesa@pw.edu.pl 
It is assumed that consolidation of soil results in its regular deformation. In turn, the presence of tangential forces results in horizontal displacement of soil. The averaged pressure value relative to the surface of contact between the wheel driving mechanism and the soil, evenly distributed on the entire surface of contact between the wheel and the base, is taken for the analysis of stresses and deformations.

Horizontal soil deformation has the greatest impact on the driving force value, while vertical soil deformation of soil - on the rolling resistance value.

The traction properties of the wheel driving mechanism cooperating with a given soil are assessed mainly based on traction forces. The traction forces include: the rolling resistance $\left(\mathrm{P}_{\mathrm{f}}\right)$, the driving force $\left(\mathrm{P}_{\mathrm{j}}\right)$ and the drawbar pull $\left(\mathrm{P}_{\mathrm{u}}\right)$. The relation between these forces is defined by the equation [13]:

$$
P_{u}=P_{j}-P_{f}
$$

The basic evaluation criterion of traction properties of the wheel driving mechanism is value of pulling force $\left(\mathrm{P}_{\mathrm{u}}\right)$. Engine power determines value of driving force of vehicle. Shear strength of the soil allows to transmission of driving force on circumference of a wheel on a soil acts as driving force $\left(\mathrm{P}_{\mathrm{j}}\right)$.

Physical of soil properties have influence on traction properties such as: cohesion, angle of internal friction and coefficients characterizing soil deformation under influence of stress propagation.

\section{Application of the finite element method and digital simulation for analysis of the vehicle-land system}

To analyse the impact of the wheel driving mechanism on the soil, Simulation Mechanical system by AutoDesk was used. The system contains the "Mechanical Event Simulation" module, which allows the user to model the properties of plastic-elastic materials and to adjust the nature of cooperation between the wheel driving mechanism and the base.

This module allows elements with non-linear strength properties. The geometric shape of models [11] may be prepared in the software environment, or a compatible file created using different software, e.g. the Autodesk Inventor, may be imported. Based on the geometric model, a grid of finite elements was created and the boundary conditions were defined. The system allows reading the resulting values (components of the stress status) in each point of a three-dimensional grid of finite elements; it also generates a map of results in a graphic form. In the case of dynamic systems, the results were saved as animation showing the movement of parts, as well as deformation and stress of the material. The values of stress and deformation components may be analysed by adding relevant viewing planes.

The designing process and simulation of the vehicle-land system was performed in a stepwise manner, as follows $[3,6,8]$ :

- creating a digital model of the wheel driving mechanism and the base,

- defining mathematical models describing the behaviour of materials,

- selecting parameters defining the properties of materials,

- configuring loads affecting the system,

- defining zones and type of contact between the driving mechanism and the base,

- defining boundary conditions,

- selecting parameters and generating the FEM grid,

- simulation,

- analysis of the obtained results. 
The vehicle-land system in this work is composed of two basic elements: the drive wheel and the strip of soil it moves on. A tire for agricultural machines (with dimensional signatures 14.9-28) was adopted for modelling. Such tires manufactured by Stomil and Good-Year were used in experimental studies conducted at the Faculty of Civil Engineering, Mechanics and Petrochemistry at the Warsaw University of Technology in a soil channel [4]. Use of the same tire geometry allowed comparing the digital simulation results with empirical results.

The digital model was exported to the Simulation Mechanical software. "joint" elements were generated in the system. These are special elements of the FEM grid used to connect elements of digital models to transfer the load $[2,9]$

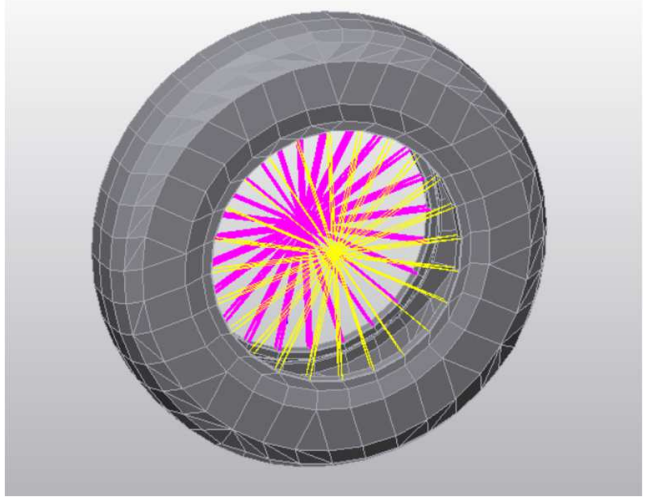

Fig. 1. View of nodes transferring loads from the wheel axis to the tire

The soil is represented by a cuboid element, which reflects the actual laboratory case in the soil channel. The base model required custom preparation of the grid in order to minimise the calculation time and to register the results in strictly specified points without the loss of the assumed accuracy. The grid was generated using the projection mechanism. The geometry of the grid, denser in the measurement points, was drawn on one of the side walls. below.

The flat grid was multiplicated into a three-dimensional form, as shown in the figure

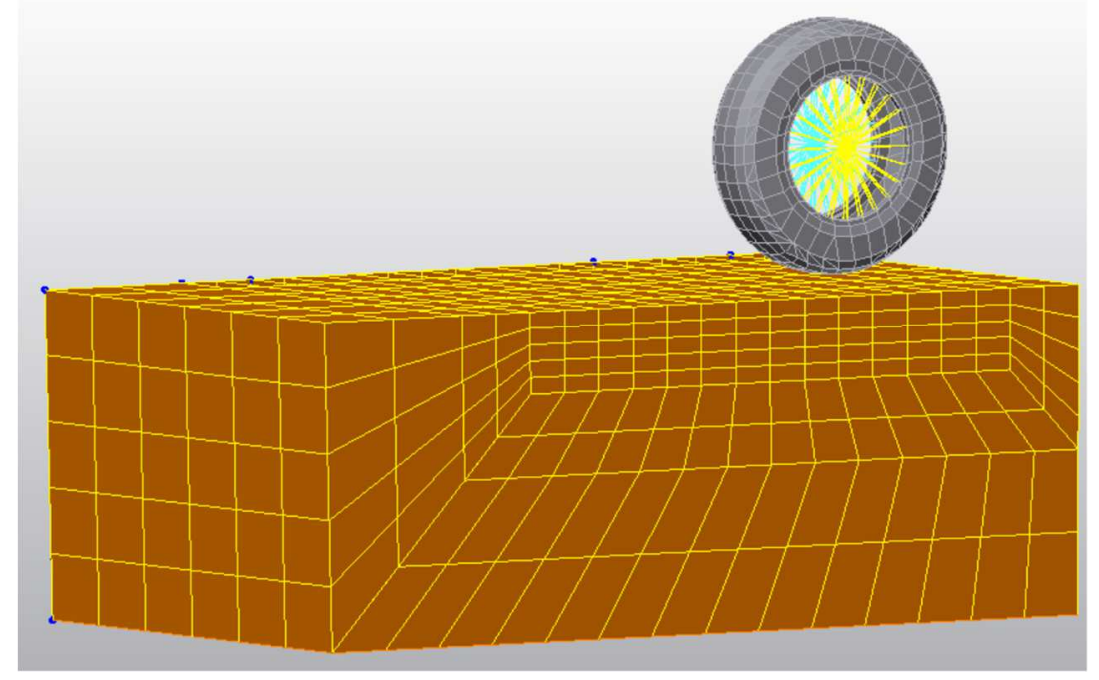

Fig. 2. Final geometric model of the vehicle-land system 
The load and kinematic parameters were modelled in the examined system with the following specification:

- pressure: $7 \mathrm{kN}$ and $10 \mathrm{kN}$,

- rotational speed of the wheel: $0.4 \mathrm{rps}$, i.e. the linear speed was set to approx. $7 \mathrm{~km} / \mathrm{h}$ (the basic value, without slippage).

The internal surface of the tire was subjected to pressure of $0.15 \mathrm{MPa}$ [4] which corresponded to the value of air pressure in a pneumatic tire. Parameters characterising the relevant material in the plastic-elastic model, e.g. density, Young's modulus and Poisson's ratio, were assigned to the individual elements of the studied system [15].

The data corresponded to a sandy-clay soil, identical to that used under laboratory conditions. The wheel slippage on the base was an additional parameter taken into account in the digital studies. Simulations were performed for the values of 10\%, 15\%, 20\%, 25\%, and $30 \%$. The studies determined the type of contact between touching surfaces and the stiffness of the contact, i.e. software parameters ensuring the required cooperation between elements in contact (tire and soil). According to the software manufacturer's recommendations, the contact stiffness is selected based on observation of the model's behaviour upon modification of the order of magnitude [1]. Each simulation presents 2 seconds of the wheel's movement. During the first second, the wheel is initially at rest and then it starts moving, in the next second - when the driving conditions are stabilised - the calculated values are verified. 20 calculation steps were assumed for one second, and thus each of the simulations included a total of 40 steps.

\section{Numerical calculations of the vehicle-land model}

The simulations were conducted using the Mechanical Event Simulation module, which is a part of the Autodesk Simulation Mechanical software. This module allows analysis of dynamic mechanical systems made of mutually cooperating elements. The cases of dynamic simulations are much more complicated than static simulations. Apart from selecting the relevant parameters, they require appropriate preparation of finite element grids, to make the cooperation between the mobile parts and the value of mutual interactions as close to reality as possible.

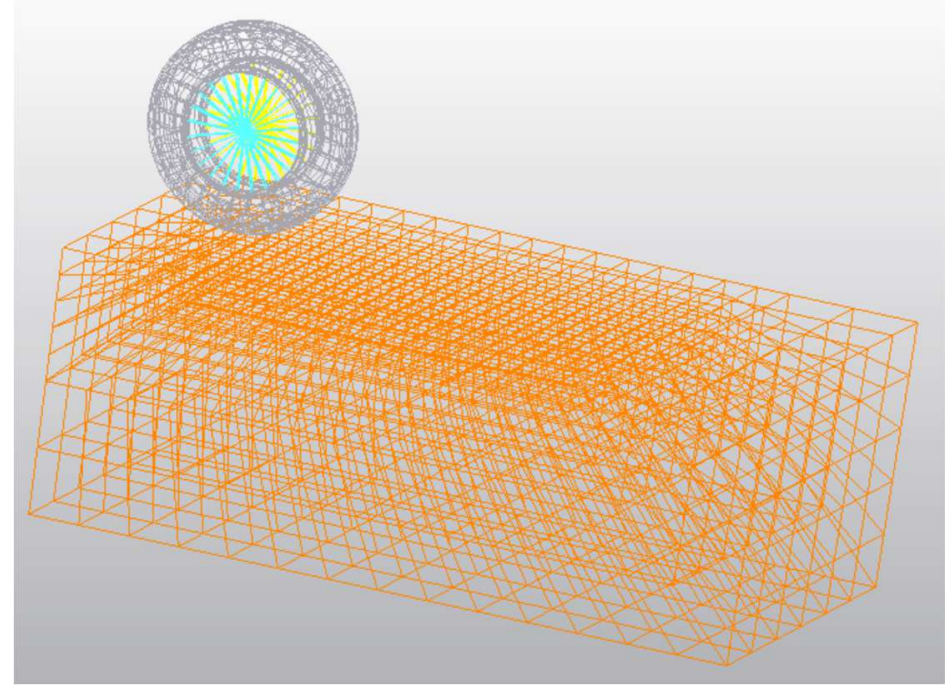

Fig. 3. View of the model grid 
The most important element of the system was the soil (plastic-elastic material), where the stress distribution was studied. The wheel grid was generated using a tool that automatically divided the part into finite elements based on a set maximum size of the element. 3760 calculation nodes, forming 9203 elements, were generated in the entire model.

After the simulations, the results were presented as color maps of the reduced stress distribution. Despite the fact that the software averages the results for the graphic presentation, the accurate values may be read only in the grid's nodes. Therefore, prior preparation of the grid in such a manner to make the selected nodes overlap the planned measurement points was essential.

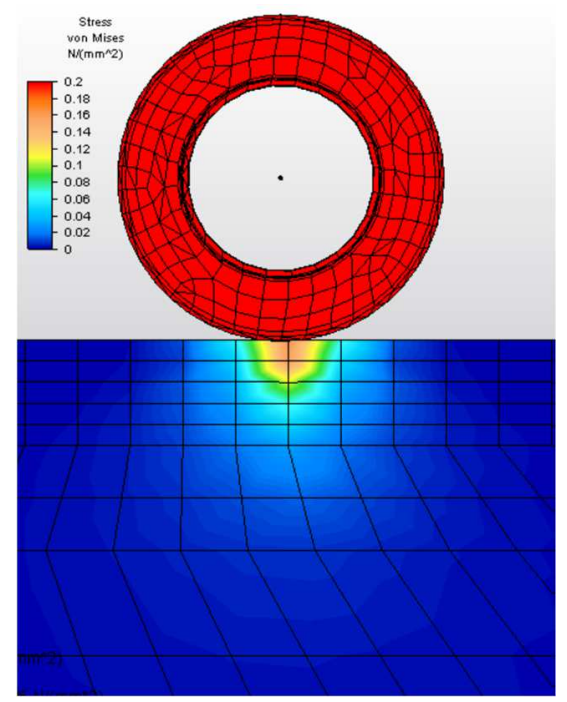

Fig. 4. Sample section along the wheel movement track, presenting the distribution of reduced stress in the soil

\section{Analysis of the obtained results}

The unknown slippage of the wheel rolling on the soil may be determined based on values calculated by the simulation software. The selection of the computing grid point makes it possible to depict the location of this point in every step of the simulation. For the first second, the wheel is initially at rest and then it starts moving; its movement is variable then. Hence, in order to determine the actual linear speed, the next second of each simulation, when the movement of the wheel is uniform and the wheel axis is moving at $V_{\mathrm{r}}$ speed, is taken into account. Accounting for the dimension of the rolling diameter of the tire $(\mathrm{D}=1358 \mathrm{~mm})$ [4] as well as the preset angular velocity $(n=0.4 \mathrm{rps})$, the theoretical speed of wheel axis $\mathrm{V}_{\mathrm{t}}$ was determined. The digital model uses unloaded tire diameter, which was changed in the MES system under the influence of applied external load [15]. As a result, the value of slippage $s$ was determined as defined by the following equation:

$$
\begin{gathered}
V_{t}=\omega R=2 \pi n R\left[\frac{\mathrm{mm}}{\mathrm{s}}\right] \\
s=\frac{V_{t}-V_{r}}{V_{t}}
\end{gathered}
$$


where:

$\mathrm{V}_{\mathrm{t}} \quad-\quad$ the theoretical speed of the wheel axis (a case where the temporary centre of the wheel rotation is located in the point of contact between the wheel and the base),

$\mathrm{V}_{\mathrm{r}} \quad$ - the actual speed of the wheel axis (the case where the temporary centre of rotation is located above the point of contact between the tire and the base),

$\mathrm{R} \quad-\quad$ the rolling radius of the drive wheel,

$\mathrm{n}, \omega \quad-\quad$ angular velocity,

$\mathrm{s} \quad-\quad$ slippage.

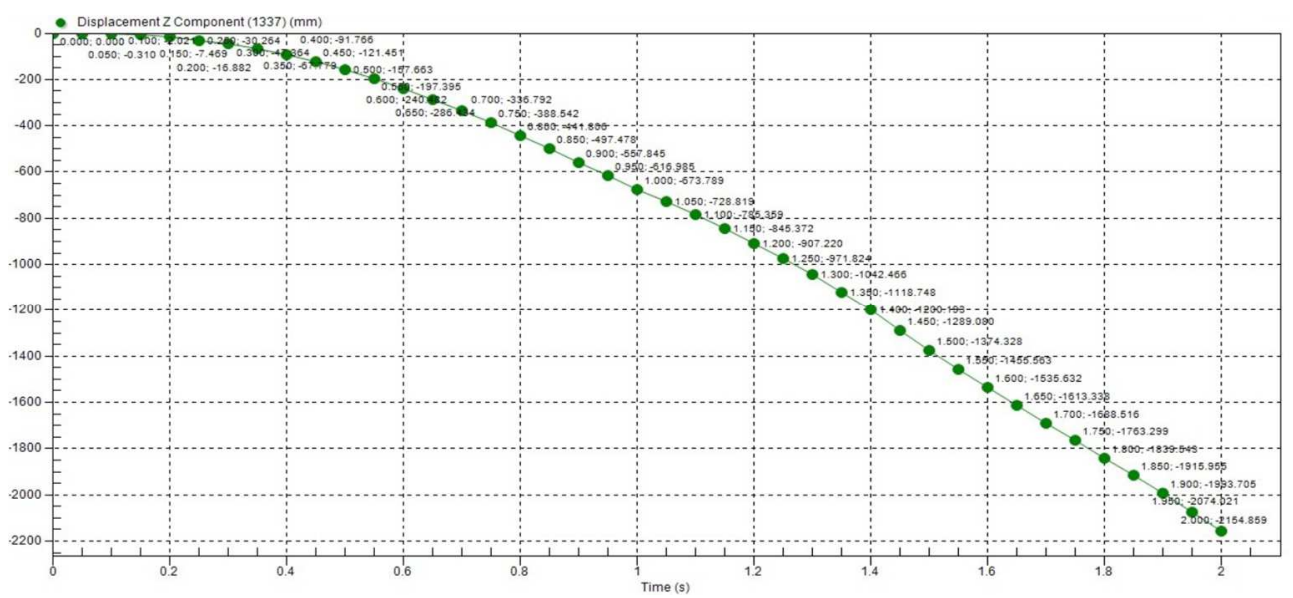

Fig. 5. Sample Sample diagram of movement of the wheel centre along the $\mathrm{Z}$ axis

The stress values generated by the system were compared to values obtained in the laboratory tests. During experimental studies in the soil canal [5], sensors measuring pressure under the wheel were located at the depth of 100, 200, 300, 400, and $500 \mathrm{~mm}$ below the soil surface. The soil model grid was adjusted to allow reading simulation results at the same depths. Sample results for sandy-clay soil and clay with pressure of $7 \mathrm{kN}$, with internal pressure in the tire is equal $0,15 \mathrm{MPa}$ (the same as the laboratory tests) [4] are presented in table 1 and table 2 .

Table 1. Stresses in sandy-clay soil, pressure force $7 \mathrm{kN}$

\begin{tabular}{|c|c|c|c|c|c|}
\hline $\begin{array}{c}\text { Depth } \\
{[\mathrm{mm}]}\end{array}$ & 100 & 200 & 300 & 400 & 500 \\
\hline slippage [\%] & \multicolumn{5}{|c|}{ reduced stress values [Kpa] } \\
\hline 10 & 51.6 & 36.4 & 24.1 & 16.4 & 10.7 \\
\hline 15 & 82.6 & 57.9 & 37.9 & 25.3 & 16.2 \\
\hline 20 & 94.3 & 66.2 & 43.5 & 28.9 & 18.4 \\
\hline 25 & 96.3 & 67.4 & 44.2 & 29.4 & 18.9 \\
\hline 30 & 98.0 & 69.2 & 45.5 & 30.4 & 19.5 \\
\hline
\end{tabular}

The stress values obtained via dynamic simulations are consistent with the values registered under laboratory conditions. A tendency to increase the stress upon the increase in slippage was observed (Table 1, Fig. 6), which is in agreement with the theory and empirical studies [14] of the vehicle-land system. This is connected with the phenomenon of reduction of the drive wheel linear speed upon the increase in slippage.

The consistency of calculation results obtained using the finite element method with results obtained under laboratory conditions was confirmed for the dynamic effect the wheel 
driving mechanism exerted on the soil. The base-recorded stress values decrease along with the increase in measurement depth, and increase along with the increase in slippage.

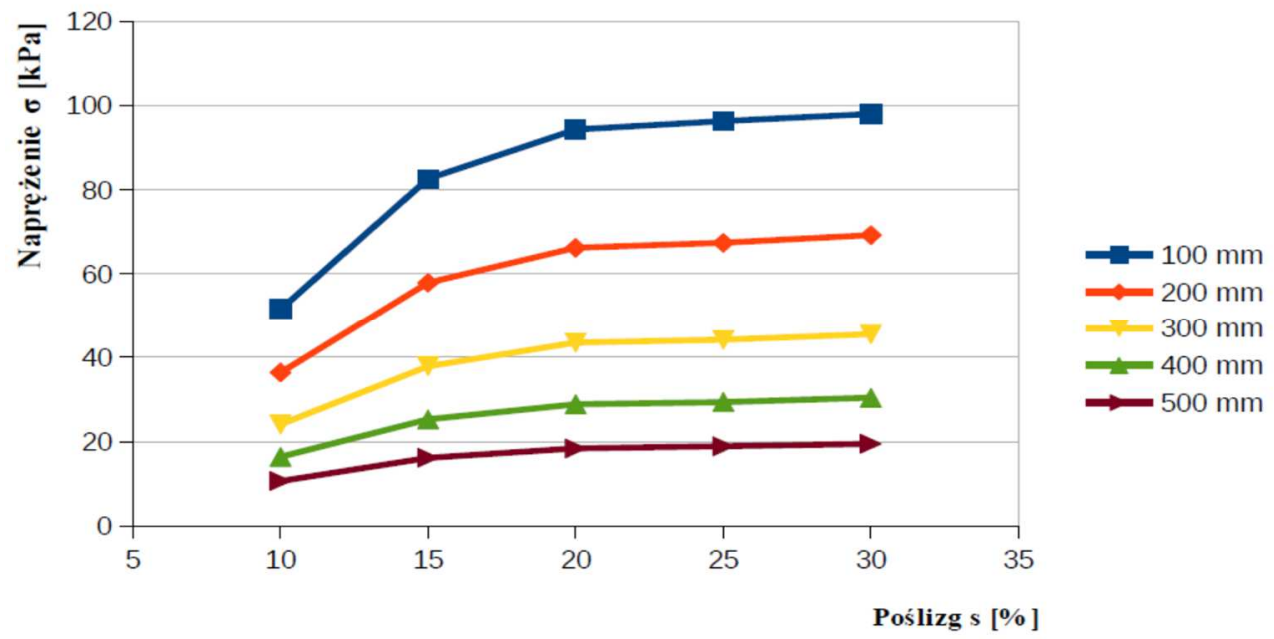

Fig. 6. Relation between stress and wheel slippage. Sandy-clay soil. Measurement depths 100$500 \mathrm{~mm}$. Pressure force $7 \mathrm{kN}$.

Hence, to reduce pressure and deformations in the base, the angular velocity of the vehicles' drive wheels should be adjusted in such a way to minimize the slippage. To obtain this, monitoring and automation systems may be used. In addition, use of FEM allows designing such a shape of the tire tread so that the slippage is as low as possible under particular dynamic conditions.

The performed approximation of calculated stress generated in the soil under the impact of the wheel driving mechanism as a function of the measurement depth makes it possible to confirm a good consistency between the obtained results and Goriaczkin's theoretical mathematical model [4].

$$
p=k \cdot z^{n}
$$

where :

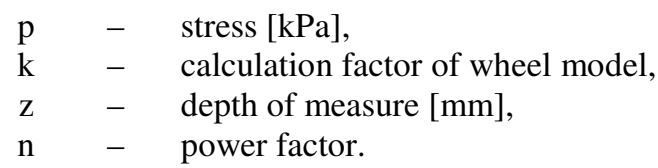

For all simulated cases, the correlation coefficient has the value of at least 0.927 . The results of approximation allow stating that the relation between stress in the soil under the impact of the dynamic load of the wheel driving mechanism and the wheel slippage is consistent with the logarithmic function $[4,11]$. The obtained correlation coefficients for this approximation case have the average value of 0.933 . However, one must pay attention to a similar accuracy of approximation with the power function; in this case the average value of the correlation coefficient was 0.921. Assuming that the results obtained via numerical simulation are consistent with the actual values, the power nature of the relation between stress generated in the soil and the wheel slippage cannot be excluded. 


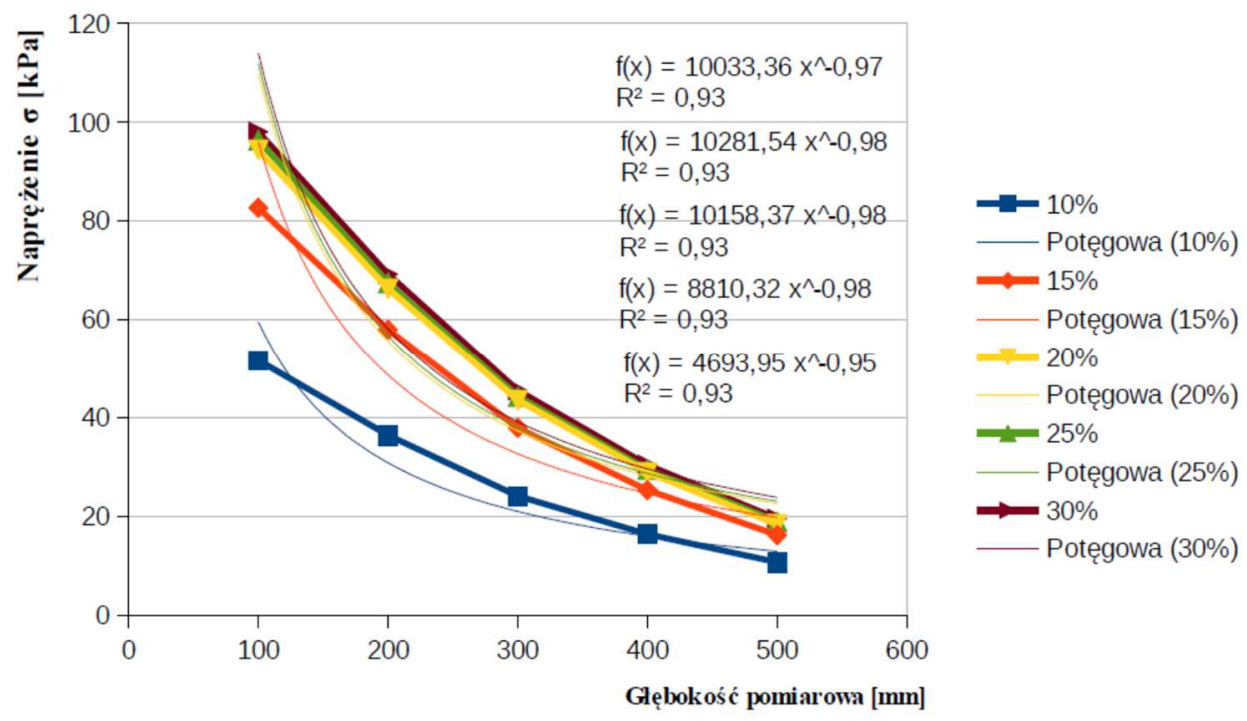

Fig. 7. Relation between stress and measurement depth, along with regression curves (sandy-clay soil, pressure force $7 \mathrm{kN}$, slippage from $10 \%$ to $30 \%$ )

Digital studies prove that the impact of slippage on stresses in the soil is considerable only at small depths. Stresses have a similar value below $0.4 \mathrm{~m}$.

\section{Conclusion}

The purpose of this study with the use of digital simulation is to reduce expenses on costly experimental studies with the use of off-road vehicles or specially developed laboratory machines. When such experiments are replaced with numerical methods, not only the cost is reduced, but also the impact of weather conditions on measurement results is avoided and the time required for the study is shortened.

However, digital simulation in the case of a vehicle-land system dynamic load is a relatively complicated task. The correctness of obtained calculation results is affected by numerous factors, including the type and density of the FEM grid, the correctness of adopted material features of the base and elements being parts of the drive wheel, etc. The preparation of high-accuracy models is time-consuming and requires good knowledge of the software. Furthermore, complicated dynamic cases require high computing power, and efficient computer systems are necessary to perform fast simulations.

The developed digital model allowed calculation of stresses, which may be deemed credible based on the previous works, as well as data from experimental studies on similar cases. During the evaluation of stresses, subjective factor was also observed i.e. the estimated selection of calculation steps, in which the wheel axis has a relevant position as compared to the soil's grid of finite elements. A very high density grid would probably eliminate this problem. However, the computing capacities of the available workstation did not allow us to develop a more accurate model.

The use of the methods allows for design and selection parameters of exploitation pneumatics drive mechanism. It leads to significantly reduce the negative impact on the natural environment by machines in agrotechnical treatments and forestry. The methods allow to improvement of the natural environment. 


\section{References}

1. Bekker M.G., Introduction to terrain-vehicle system, The University of Michigan Press, Ann Arbor, (1969)

2. Błaszkiewicz Z., A method for the determination of the contact area beteween tire and the ground. Journal Of Terramechanics,. 27, 4, (1990)

3. Król K., Metoda elementów skończonych w obliczeniach konstrukcji, Wydawnictwo Politechniki Radomskiej, Radom, (2006)

4. Jakliński L., Mechanika układu pojazd-teren w teorii i badaniach, Oficyna Wydawnicza Politechniki Warszawskiej, (2006)

5. Lee J. H., Finite element modeling of interfacial forces and contact stresses of pneumatic tire on fresk snow for combined longitudinal and lateral slips, Jouranl of Terramechanics, 48, 3, June, (2011)

6. Malesa W., Korzybski W., Zastosowanie MES w obliczeniach parametrów współpracy opony z glebą z uwzględnieniem wybranych aspektów dynamiki układu, Mechanik 1, pp. 73, 9, (2010).

7. Muro T., O'Brein J., Terramechanics. Land Locomotion Mechanics, A. A. Belkema Publishers, (2004)

8. Olszewski Z., Waluś K., Berdychowski M., Modelowanie cech geometrycznych opony pneumatycznej z zastosowaniem metody elementów skończonych. „Czasopismo Logistyka”, (2014)

9. Ozaki S., Hinata K., Senatore C., Iagnemma K., Finite element analysis of periodic ripple formation under rigid wheel, Jouranl of Terramechanics, 61, 3, October (2016)

10. Pytka J., Dynamics of wheel-soil systems, CRC Press, (2013)

11. Stasiak W.: Analiza modeli opisujących rozkład naprężeń w glebie, Journal of Research and Applications in Agricultural Engineering, Poznań, 53, 2, str. 39-43, (2008)

12. Stasiak W., Modele propagacji nacisków w glebie generowanych przez oponę, praca doktorska, Politechnika Warszawska, (2003)

13. Stołyński A., Mechanika układu pojazd-teren, Wydawnictwo Ministerstwa Obrony Narodowej, 1966.

14. Wong J. Y., Terramechanics and off-road vehicle engineering, Elsevier Ltd., (2010)

15. Zabielski M., Model symulacji propagacji naprężeń w glebie generowanych przez opony maszyn rolniczych, praca doktorska, Politechnika Warszawska, (2015) 